\title{
Mechanical Stability Diagrams for Thermal Barrier Coating Systems
}

\author{
Mario Rudolphi ${ }^{1} \cdot$ Mathias Christian Galetz $^{1} \cdot$ Michael Schütze $^{1}$
}

Submitted: 22 July 2020/in revised form: 17 December 2020/Accepted: 11 January 2021 / Published online: 9 February 2021

(C) The Author(s) 2021

\begin{abstract}
Loss of mechanical integrity due to thermal aging and subsequent spallation of the ceramic top layer is one of the dominant failure mechanisms in thermal barrier coating systems. In order to predict and avoid such mechanical failure, a strain-based lifetime assessment model is presented for a novel double-layer thermal barrier system. The investigated ceramic system consists of a gadolinium zirconate layer on top of a layer of yttria-stabilized zirconia prepared by atmospheric plasma spraying. The mechanical stability diagrams generated by the model delineate areas of safe operation from areas where mechanical damage of the thermal barrier coating becomes imminent. Intensive ceramographic inspection is used to investigate the defect growth kinetics in the ceramic top coat after isothermal exposure. Four-point bending experiments with in situ acoustic emission measurement are utilized to determine the critical strain to failure. The results are then used to generate mechanical stability diagrams for the thermal barrier coatings. From these diagrams, it becomes evident that the gadolinium zirconate layer has significantly lower strain tolerance than the yttriastabilized zirconia. However, the underlying yttria-stabilized zirconia layer will provide some thermal protection even when the gadolinium zirconate layer has failed.
\end{abstract}

Keywords acoustic emission measurement $\cdot$ critical strain $\cdot$ defect growth $\cdot$ four-point bending $\cdot$ mechanical failure $\cdot$ mechanical stability diagram $\cdot$ thermal barrier coating

Mario Rudolphi

mario.rudolphi@dechema.de

1 DECHEMA-Forschungsinstitut, Theodor-Heuss-Allee 25, 60486 Frankfurt am Main, Germany

\section{Introduction}

Thermal barrier coating (TBC) systems are a vital part of state-of-the-art turbine engines providing a thermal gradient between the combustion gas environment and base metal of the structural component. TBC systems usually consist of a ceramic top coat and a metallic bond coat layer on Ni-base superalloy material. While the ceramic top coat provides low thermal conductivity, the metallic bond coat ensures good oxidation resistance and improved bonding to the substrate. The benefit of such coatings is a reduced cooling effort and lower metal temperatures and thus longer component lifetime and increased efficiency (Ref 13). Over the last decades, yttria-stabilized zirconia (YSZ) has been established as the standard material for the ceramic top coat, due to its low thermal conductivity, relatively high coefficient of thermal expansion and high strain tolerance. However, increased sintering and phase transformations limit the use of YSZ for long-term operation to temperatures below $1200{ }^{\circ} \mathrm{C}$ (Ref 3-5). For further improvement of turbine efficiency and component lifetime, it is therefore necessary to evaluate new materials with better phase stability up to very high temperatures and ideally even lower thermal conductivity. Gadolinium zirconate (GZO) is one material among a list of possible candidates that satisfies these requirements (Ref 6), however, it also exhibits a reduced fracture toughness compared with YSZ (Ref 7). To benefit from the excellent phase stability and low thermal conductivity of GZO and also from the superior mechanical stability of YSZ, a double-layer concept was proposed (Ref 8, 9). In this work, a double-layer system prepared by atmospheric plasma spraying (APS) was investigated.

In recent years, the protective capability of thermal barrier coatings has been incorporated into the design of 
gas turbines and thus the loss of the ceramic coating has significant negative impact on the remaining lifetime of e.g., turbine blades, vanes or heat shield plates. Consequently, lifetime assessment of thermal barrier coating systems is an important necessity (Ref 10). High-temperature exposure of ceramic materials induces sintering and an increase in stiffness with prolonged exposure. Furthermore, in the case of thermal barrier coatings, oxidation of the bond coat leads to the formation of an alumina interlayer (thermally grown oxide, TGO) between the metallic bond coat and the ceramic top coat, which induces growth stresses into the system (Ref 11, 12). Upon cooling to room temperature the thermal mismatch stresses in combination with those two effects will result in an increase of damage that is introduced into the ceramic top coat with prolonged exposure. As a consequence, the length of cracks and defects in the ceramic is increasing. According to Griffith's theory of brittle failure (Ref 13), the critical stress to failure of ceramic (brittle) materials is inversely proportional to the square root of the size of the largest defect present in the ceramic system. Hence, the mechanical properties of a ceramic coating can be representative of the degradation state of the ceramic material, in terms of microcrack formation and previous works have shown that four-point bending can be a suitable tool to investigate the mechanical degradation of TBC materials (Ref 14). The objective of this work was therefore to assess the strain tolerance of the ceramic top coatings when subjected to bending load (i.e., their critical strain values) and from these results to develop a novel fracture mechanics-based model for lifetime assessment of thermal barrier coatings. An intensive analysis of the microcrack network and defect structure of the coatings was carried out in combination with four-point bending experiments to investigate the aging effect on crack growth and the mechanical properties of the ceramic top coat. The results were combined with physical property data (Ref 15) from our project partners to establish mechanical stability diagrams that allow identification of areas of safe operation and of areas where mechanical failure is impending.

\section{Experimental}

\section{Sample Preparation and Isothermal Oxidation}

Single crystal nickel-based superalloy PWA 1483 was used as substrate material. Bending bars $\left(80 \times 10 \times 5 \mathrm{~mm}^{3}\right)$ were cut by electrical discharge machining (EDM) from the material so that the $\langle 100\rangle$ orientation is along the length of the bending specimen. A $2 \mathrm{~mm}$ deep notch of $20 \mathrm{~mm}$ width was machined into the bottom side of the specimen to intentionally weaken the bending bar in an area between the inner loading points. This is to avoid that damage of the ceramic top coat during the bending test originates from the loading points. After preparation of individual bending bars from the substrate material, the thermal barrier coatings were applied by an industrial partner. Two coating systems were investigated in this study, each with two levels of porosity. The first system S1 is a standard TBC with a single-layer ceramic coating consisting of a $500 \mu \mathrm{m}$ thick $8 \mathrm{wt} . \%$ yttria-stabilized zirconia (8YSZ) layer prepared by atmospheric plasma spraying (APS) on top of a $330 \mu \mathrm{m}$ thick bond coat layer of NiCoCrAlY (LCO22) prepared by vacuum plasma spraying (VPS). The second system S2 consisted of an identical bond coat and a double-layer ceramic approach, comprising a $400 \mu \mathrm{m}$ thick layer of gadolinium zirconate $\left(\mathrm{Gd}_{2-}\right.$ $\mathrm{Zr}_{2} \mathrm{O}_{7}, \mathrm{GZO}$ ) on top of a $100 \mu \mathrm{m}$ thick layer of 8YSZ. To investigate the effect of porosity on defect/crack growth and mechanical stability, the ceramic top coats were produced with two different porosity levels: (1) a lower porosity level of nominal 5-9\%, labelled LP, and (2) a higher level of nominal 16-20\%, labelled HP. Both doublelayer coatings were produced using a low-porosity (LP) YSZ bottom layer and varying only the porosity of the GZO top layer. The coating porosity was verified in the assprayed state using cross-sectional SEM images and image analytical methods and mercury intrusion (Ref 15). Figure 3 shows SEM images of the four different coating variants in the as-sprayed state to illustrate the coating microstructure after processing.

Different levels of damage were introduced into the coating system by isothermal oxidation of the specimens in a box furnace at $1050{ }^{\circ} \mathrm{C}$ for durations up to $1500 \mathrm{~h}$ in laboratory air. A second set of samples was oxidized at $1100{ }^{\circ} \mathrm{C}$ for durations up to $500 \mathrm{~h}$. An overview of the sample nomenclature and oxidation conditions is given in Table 1. Micrographs of the coating systems after oxidation are given in Fig. 4. Several cracks are marked in the micrographs with red ellipses.

\section{Mechanical Testing}

Four-point bending was performed on a universal testing machine (Hegewald \& Peschke, InspectTable50) using a self-designed bending setup. Acoustic emission measurement was utilized for in situ detection of microcracking within the ceramic top layer during the bending test. Acoustic signals were recorded using a Physical Acoustics PCI card with amplifiers of type 20/40/60 and WD sensors. A setup with two sensors was used to eliminate unwanted noise signals and to discriminate the inner region of the sample with the linear location technique. Due to the size limitation within the bending setup, the sensors were attached to the specimen via wave-guide wires by spot 
welding. Figure 1 illustrates the setup of the bending experiment and a typical result data set. The bending geometry used for the current investigation was $64 \mathrm{~mm}$ distance between the outer load points and $36 \mathrm{~mm}$ between the inner load points. Load point displacement was measured using a linear variable differential transformer (LVDT). The displacement data were converted into strain data by a solution of the Euler-Bernoulli beam equation assuming linear elastic behavior of the materials. The beam equation was set up for a composite bending bar with three layers (substrate, bond coating and ceramic top coating) and it accounts for the individual Young's modulus and thickness of each layer. Please note that, the ceramic top coating was not subdivided in the analysis of the GZO/YSZ double-layer system. A shape change of the metallic substrate (i.e., deformation) is also not considered by the beam equation. Since the strain in a beam under bending is a function of the distance to the neutral fiber (geometrical position in the bending bar where there is no stress or strain upon bending) and the observed failure modes originate at different height in the beam, the strain was evaluated at different positions for each failure mode. Table 2 lists the possible failure modes and the position within the bending beam at which the corresponding experimental strain value was calculated. The critical strain to coating failure $\varepsilon_{\mathrm{c}}$ was defined as the first significant increase in acoustic emission (see Fig. 1b). It should be noted that due to limitations in sample numbers no statistical evaluation of critical strain values was performed. The resolution of the measurement setup is $<0.005 \%$ strain, and hence individual measurement results are given with two digits after the decimal point. However, the statistical variation is believed to be around $\pm 0.05 \%$ strain.

\section{Microstructural Investigation}

After the bending test, the samples were vacuum-embedded in epoxy resin for ceramographic inspection. Cross sections of the unstrained part of the specimens were prepared to study the microstructure of the ceramic coating after oxidation and to investigate the crack and/or defect growth. Up to six SEM overlapping images were taken side by side at moderate magnification of $100 x$ to cover a length of about $4 \mathrm{~mm}$ for crack/defect analysis. The images were subsequently stitched to a panoramic image and length and orientation of defects/cracks were analyzed. Since no

Table 1 Sample nomenclature and oxidation conditions.

\begin{tabular}{|c|c|c|c|c|c|}
\hline Nomenclature & Type & Top coating & Porosity level & Bond coating & Oxidation \\
\hline S1 HP & Single-layer TBC & $8 Y S Z, 500 \mu \mathrm{m}$ & $16-20 \%$ & NiCoCrAlY, $330 \mu \mathrm{m}$ & $1050{ }^{\circ} \mathrm{C}: 100 \mathrm{~h}, 500 \mathrm{~h}, 1500 \mathrm{~h}$ \\
\hline S1 LP & & & $5-9 \%$ & & $1100^{\circ} \mathrm{C}: 100 \mathrm{~h}, 300 \mathrm{~h}, 500 \mathrm{~h}$ \\
\hline \multirow[t]{2}{*}{ S2 HP } & Double-layer TBC & $\mathrm{GZO}, 100 \mu \mathrm{m}$ & GZO: $16-20 \%$ & & $1050{ }^{\circ} \mathrm{C}: 100 \mathrm{~h}, 500 \mathrm{~h}, 1000 \mathrm{~h}$ \\
\hline & & $8 Y S Z, 400 \mu \mathrm{m}$ & YSZ: 5-9\% & & $1100{ }^{\circ} \mathrm{C}: 100 \mathrm{~h}, 300 \mathrm{~h}, 500 \mathrm{~h}$ \\
\hline \multirow[t]{2}{*}{ S2 LP } & & & GZO: $5-9 \%$ & & \\
\hline & & & YSZ: 5-9\% & & \\
\hline
\end{tabular}
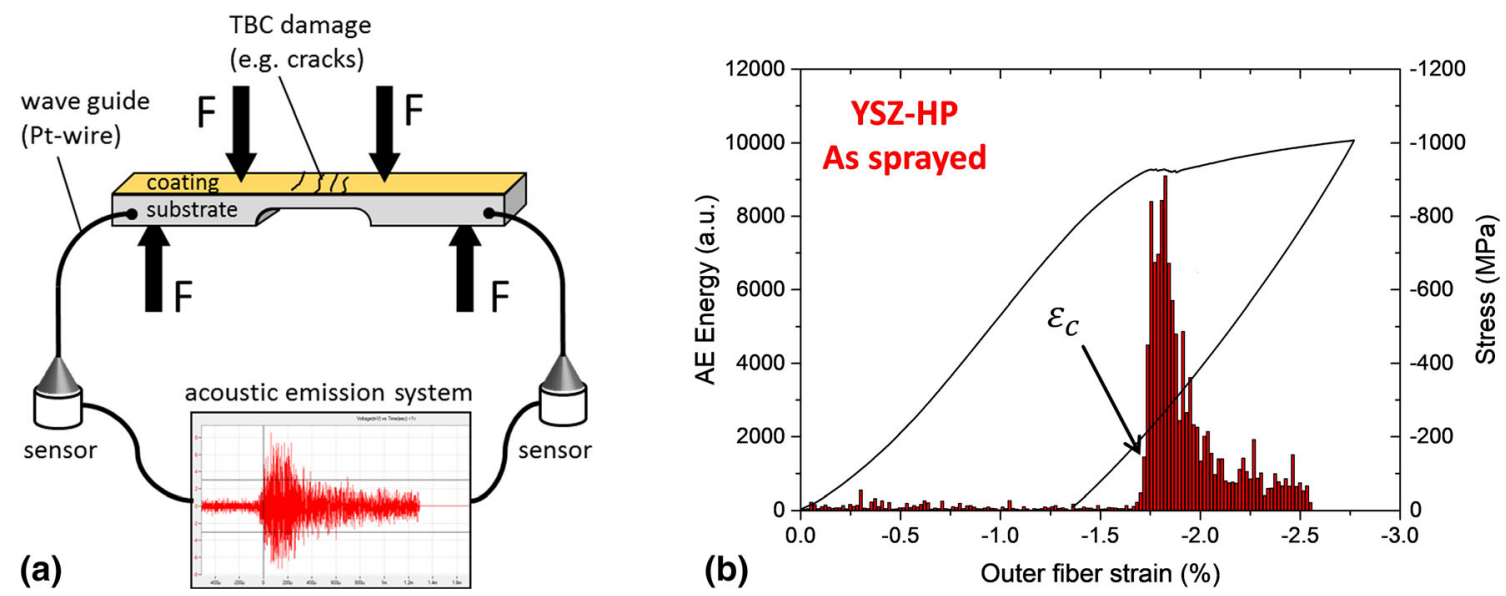

Fig. 1 Schematic illustration of four-point bending setup with in situ acoustic emission measurement (a), and typical result data set (b) with acoustic signals (red bars) and stress-strain curve (line). The onset of significant acoustic emission is used to define the critical strain $\varepsilon_{\mathrm{c}}$. 
robust method for software-automated crack detection could be found, manual marking of the cracks was performed on the stitched SEM image using the software package FIJI (Ref 16). Figure 2 provides a schematic representation of the analysis strategy. Please note that, when cracks or pores are located in close neighborhood they may start to interact. As a consequence, the effective length of the total crack/pore-field has to be considered in fracture mechanical considerations. A summary of crack interaction rules is given in (Ref 17). These rules were applied in the context of the crack analysis. In the following, the term crack will also be used as a synonym for the effective length of a crack field. The marked cracks were analyzed in terms of their orientation with respect to the ceramic/bond coat interface and length, resulting in six different categories of cracks. Firstly, cracks were categorized according to the failure mode they will most likely trigger. Cracks which are almost parallel to the interface $\left(0^{\circ} \leq \alpha \leq 30^{\circ}\right.$, where $\alpha$ is the angle between the bond coat/ ceramic-interface and the crack) were categorized as "delamination", cracks that lie around $45^{\circ}\left(30^{\circ}<\alpha<60^{\circ}\right)$ were categorized as "shear", and cracks which run mostly orthogonal to the interface $\left(60^{\circ} \leq \alpha \leq 90^{\circ}\right)$ were categorized as "segmentation". Secondly, a distinction with regards to their position in the ceramic was made, splitting the above categories into two parts, depending on whether they mostly lie within the YSZ or GZO layer. Figure 3 gives a graphical representation of the statistics observed on GZO/YSZ coatings after crack detection. Figure 3(a) and (c) shows the histogram data for the individual crack categories, while Fig. 3(b) and (d) summarizes the data in the form of box-plots. As can be seen from the figure, the limited number of cracks obtained by the manual analysis and the successive categorization result in only few categories with a reasonable number of data points. Hence, an automated and verified approach for crack detection should be strived for, especially when usage of the presented model is planned in industrial applications. For the aims of this work, a number of 100-150 cracks were identified and analyzed in the stitched SEM image of each specimen.
Table 2 Mechanical failure types for the investigated singlelayer and double-layer TBC systems under bending conditions

\begin{tabular}{llll}
\hline Failure type & Loading & \multicolumn{1}{c}{ Experimental strain evaluated at } & Modelling equation \\
\hline GZO segmentation & Tension & GZO top surface & 3.4 \\
YSZ segmentation & Tension & GZO/YSZ interface ${ }^{(a)} /$ YSZ top surface & 3.4 \\
GZO delamination & Tension & GZO/YSZ interface & 3.2 \\
YSZ delamination & Tension & YSZ/BC interface & 3.2 \\
GZO delamination failure & Compression & GZO/YSZ interface (not observed) & 3.3 (not used) \\
YSZ delamination failure & Compression & YSZ/BC interface (not observed) & 3.3 (not used) \\
GZO shear failure & Compression & GZO top surface & 3.5 \\
YSZ shear failure & Compression & YSZ top surface & 3.5 \\
\hline
\end{tabular}

(a) Indistinguishable from GZO segmentation in double-layer TBCs, thus not evaluated for double-layer TBCs
Fig. 2 Categorization of defects/cracks with respect to the three corresponding failure modes and SEM image illustrating the different defect orientations.

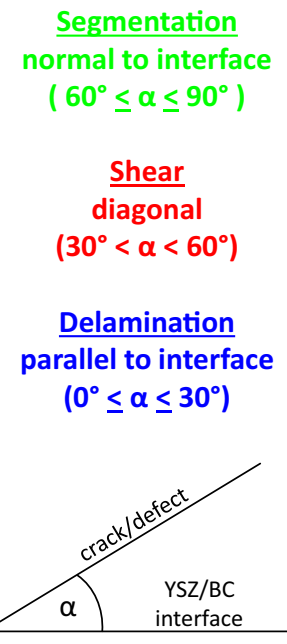




\section{Modelling Approach}

A fracture mechanics approach was used to evaluate the remaining lifetime of the thermal barrier coating systems. The approach is based on the theory of brittle failure by Griffith and subsequent modifications by Irwin (Ref $13,18)$. According to their work, the failure stress $\sigma_{\mathrm{c}}$ is inversely proportional to the square root of the size of the physical defect $c$ which causes failure. The proportionality constant $K_{\mathrm{c}}$ is the fracture toughness and is a material property.

$\sigma_{\mathrm{c}}=\varepsilon_{\mathrm{c}} \cdot E \propto \frac{K_{\mathrm{c}}}{\sqrt{\pi c}}$

where $\varepsilon_{\mathrm{c}}$ is the critical elastic strain and $E$ the Young's modulus of the brittle material. The fracture toughness value is dependent on the fracture mode. Either $K_{\text {Ic }}$ or $K_{\text {IIc }}$ are used for mode I (tensile crack opening) or mode II (shear failure). Not many experimental $K_{\text {IIc }}$ data is available in literature and usually it is expected that $K_{\text {Ic }} \leq K_{\text {IIc }}$, therefore using $K_{\text {Ic }}$ is at least a conservative approximation (Ref 19). For the different failure modes that can occur in a three-dimensional body, Eq (3.1) can be modified to yield (Ref 19):

\section{Results and Discussion}

\section{Defect Analysis/Crack Growth Kinetics}

Microstructures of the investigated coatings are given in Figs. 4 and 5 for the as-sprayed state and after oxidation at $1050{ }^{\circ} \mathrm{C}$, respectively. This is to illustrate the pore structure of the coatings as well as the development of cracks in the coating during oxidation. From a fracture mechanical standpoint, the largest crack is most likely to initiate failure of a brittle material. Hence, the maximum effective crack length (while applying the crack interaction rules) was used in the modeling approach. Figure 6 shows the maximum detected crack length in the YSZ single-layer TBCs for the three different categories segmentation, shear and delamination as a function of exposure time at $1050{ }^{\circ} \mathrm{C}$. The data from the low-porosity coating are plotted with closed symbols; the data for the high-porosity coating are plotted using open symbols. As can be seen, the high-porosity coatings exhibit higher crack length values for the categories delamination and shear. Only the segmentation cracks oriented orthogonal to the coating surface show little difference between the high- and the low-porosity variant of the YSZ coating. This can be attributed to the

\begin{tabular}{|c|c|c|c|c|}
\hline & Tension & & Compression & \\
\hline Delamination & $\varepsilon_{\mathrm{c}}^{\mathrm{del}+}=\frac{2 K_{\mathrm{c}}}{f \cdot E_{\mathrm{TBC}} \cdot \sqrt{\pi c}}$ & (3.2) & $\varepsilon_{\mathrm{c}}^{\mathrm{del}-}=-\frac{K_{\mathrm{c}}}{f \cdot \sqrt{\pi c}} \cdot \frac{(1+r / d)(1+v)}{2 E_{\mathrm{TBC}}}$ & (3.3) \\
\hline Through & $\varepsilon_{\mathrm{c}}^{\mathrm{seg}+}=\frac{K_{\mathrm{c}}}{f \cdot E_{\mathrm{TBC}} \cdot \sqrt{\pi c}}$ & (3.4) & $\varepsilon_{\mathrm{c}}^{\mathrm{sh}-}=-\frac{2 K_{\mathrm{c}}}{f \cdot E_{\mathrm{TBC}} \cdot \sqrt{\pi c}}$ & (3.5) \\
\hline
\end{tabular}

With $d$ the thickness of the ceramic coating, $r$ the ceramic/bond coat interface roughness and $v$ the Poisson's ratio of the ceramic. The factor $f$ is a geometry parameter that depends on the shape and the orientation of the defect. Usually, values between 0.63 and 1.12 are considered corresponding to a semicircular surface notch of radius $\mathrm{c}$ and a surface notch of infinite length (Ref 19-21), respectively. For this work, the combined expression $K_{\mathrm{c}} / f$ was derived from the experimental data, since the shape factor $f$ is unknown in systems with microcrack networks. The fracture toughness can nevertheless be estimated by picking a certain value for $f$ or just assuming unity.

A delamination in compressive loading was not observed for the studied thermal barrier coatings, indicating a good adhesion between bond coat and ceramic top coat. When adhesion between both layers is good, simultaneous shear-failure and delamination may occur. The set of Eq (3.2) to (3.5) can be used for all brittle ceramic layers. microstructure of APS coatings, where the boundaries between the individual splats are mostly parallel to the bond coat/YSZ interface or are rather slightly tilted with respect to that interface. The intersplat boundaries can-to some extent-be viewed as weak points in terms of mechanical strength of the ceramic material and may provide a template for crack propagation. Consequently, the microstructure of APS coatings is promoting crack growth in the two categories delamination and shear. Segmentation cracks originating from the TBC top surface have no intersplat boundaries to follow and will often be deflected into other orientations rather than growing at high rates. Note, there is also a technical limit in the length of segmentation and shear cracks due to the finite thickness of the ceramic coating and the way the crack categories are defined. A segmentation crack in a $500 \mu \mathrm{m}$ ceramic layer can be up to $577 \mu \mathrm{m}$ long when complying with the categorization rules above.

The maximum defect size detected in the double-layer GZO/YSZ coatings is depicted in Fig. 7 for the lowporosity variant (a) and for the high-porosity coating (b), 
S2 LP, as-sprayed - GZO LPYSZ LP
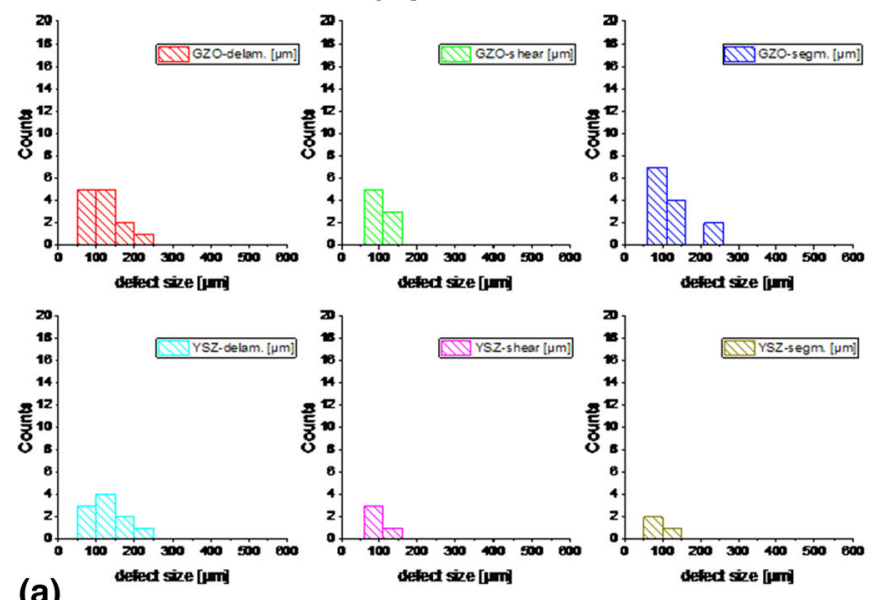

(a)

sed size $[\mu m]$

S2 LP, $1050^{\circ} \mathrm{C}, 1000 \mathrm{~h}$ - GZO LPYSZ LP
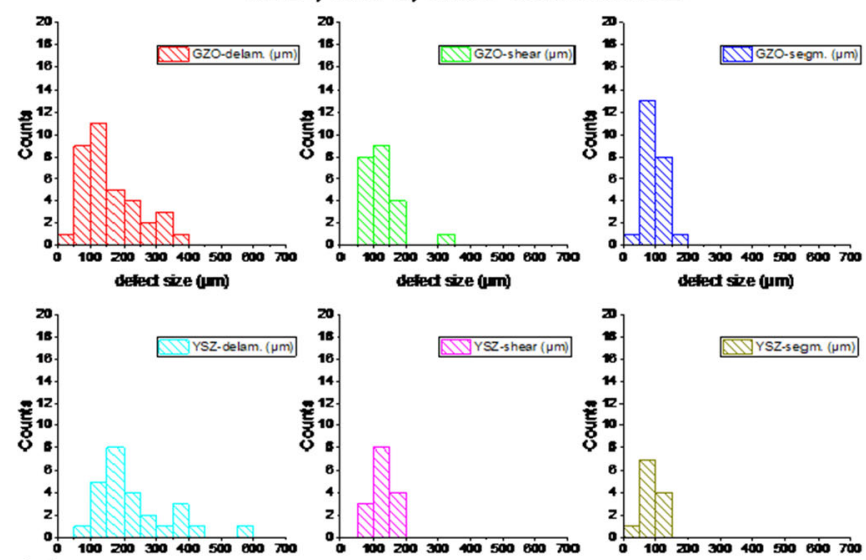

(c)
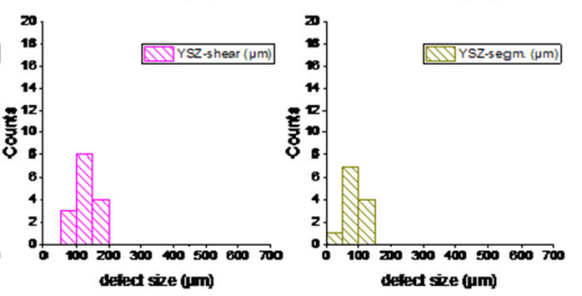

S2 LP, as-sprayed - GZO LPNSZ LP

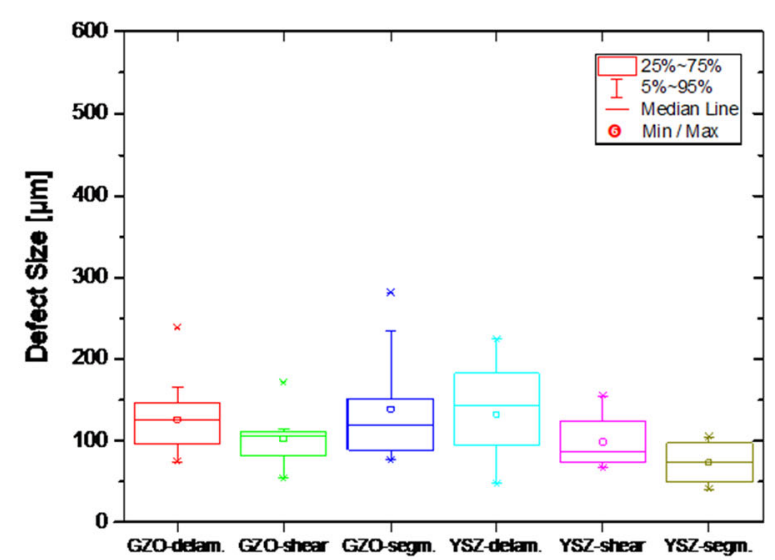

(b)

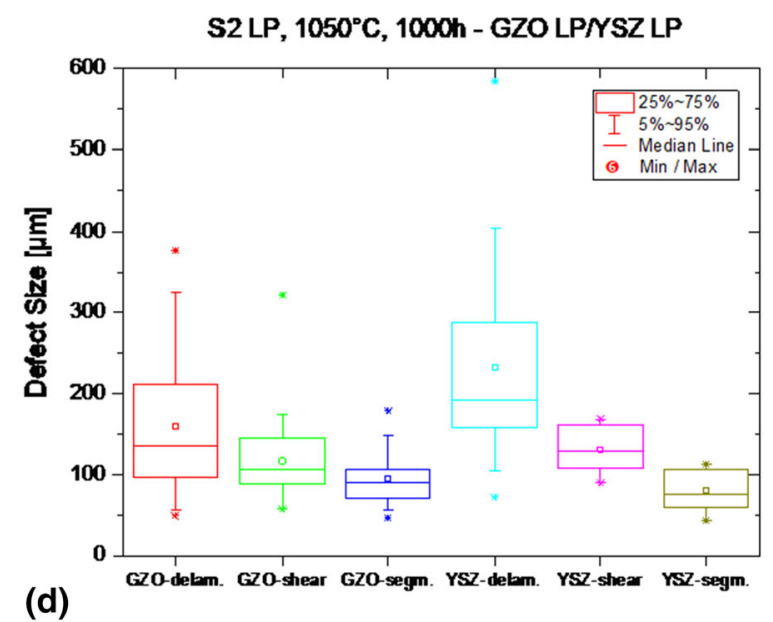

Fig. 3 Statistic representation of the categorized crack/defect length measurements of GZO/YSZ thermal barrier coatings in the as-sprayed state (a) and (b) and after $1000 \mathrm{~h}$ of oxidation at $1050{ }^{\circ} \mathrm{C}$ (c) and (d).

respectively. The cracks categorized as delamination have the highest magnitude and growth rates, as was observed for the single-layer YSZ coatings. All categories show a more or less increasing trend with prolonged oxidation time. The strongest increase is observed for the delamination cracks, while the segmentation cracks show a rather stagnant behavior with only very little increase. The delamination cracks in the low-porosity coating seem to grow faster and to higher values than in the high-porosity coatings. It seems that the high-porosity coating is able to accommodate stresses better, possibly by diluting stress amplitudes in the microcrack network and around pores.

\section{Mechanical Testing}

A typical test result obtained from a four-point bending test of a GZO/YSZ double-layer coating under compressive loading is given in Fig. 8. Two distinct peaks arise in the acoustic emission signal (red bars) mostly coincident with a drop in the stress-strain curve (black line), Fig. 8(a). The two peaks labelled "1." and "2." correspond to failure of the GZO top ceramic layer and failure of the underlying YSZ ceramic layer, respectively. Photographs of the sample during the test at the individual time points (Fig. 8b) show that at point "1." the top GZO layer has developed shear cracks and is delaminating from the underlying YSZ layer. At point " 2. " the YSZ layer is also cracked and is delaminating from the metallic compound (i.e., bond coat and superalloy). As mentioned above, the sudden increase in the acoustic emission signal was used to define the critical strain to failure of the GZO top layer and the YSZ bottom layer. In a very similar manner, segmentation failure and delamination failure can be distinguished from the acoustic emission signals under tensile loading of the four-point bending specimen. 
Fig. 4 SEM images (BSE coatings in the as-sprayed state. (a) system S1-LP, (b) system S1-HP, (c) system S2.LP and (d) system S2-HP. mode) of the investigated
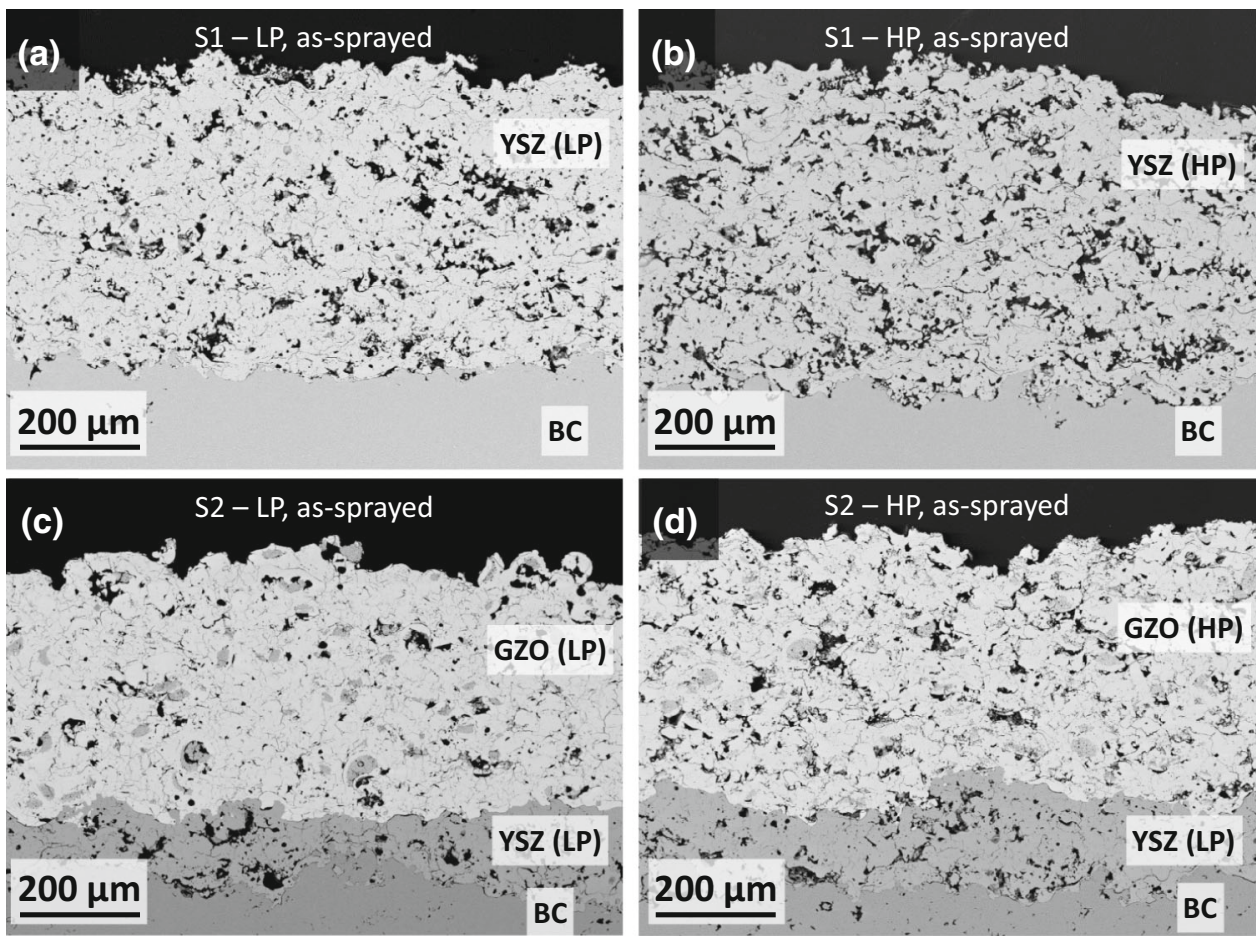

Fig. 5 SEM images (BSE mode) of the investigated coatings after oxidation at $1050{ }^{\circ} \mathrm{C}$ for $1500 \mathrm{~h}$ (system $\mathrm{S} 1$ ) and $1000 \mathrm{~h}$ (system S2) (a) system S1-LP, (b) system S1-HP, (c) system S2.LP and (d) system S2-HP. Some cracks are marked with red ellipses.
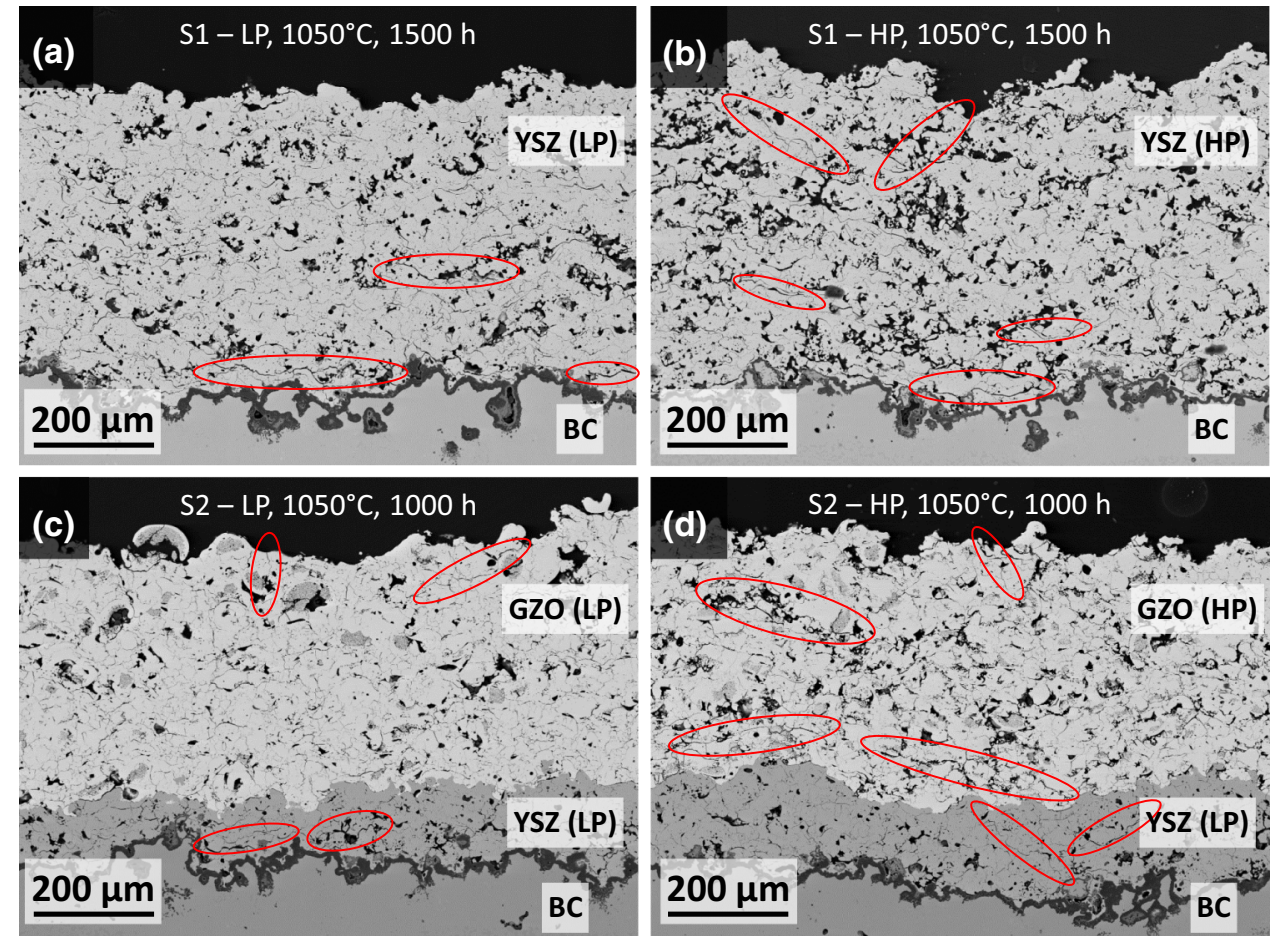

Figure 9 summarizes the results of the four-point bending tests on the single-layered YSZ coatings with high and low porosity after oxidation at $1050{ }^{\circ} \mathrm{C}$ (Fig. 9a) and $1100{ }^{\circ} \mathrm{C}$ (Fig. 9b). Open symbols are used in the plot for the high-porosity variant YSZ-HP of the coating, whereas closed symbols are used for the low-porosity variant YSZ-
LP of the coating. Only one failure mode was observed under compressive loading conditions: all samples developed a large shear crack traversing diagonally through the ceramic layer. This was instantaneously followed by delamination of the YSZ ceramic along the ceramic/bond coat interface. No distinction between shear failure and 


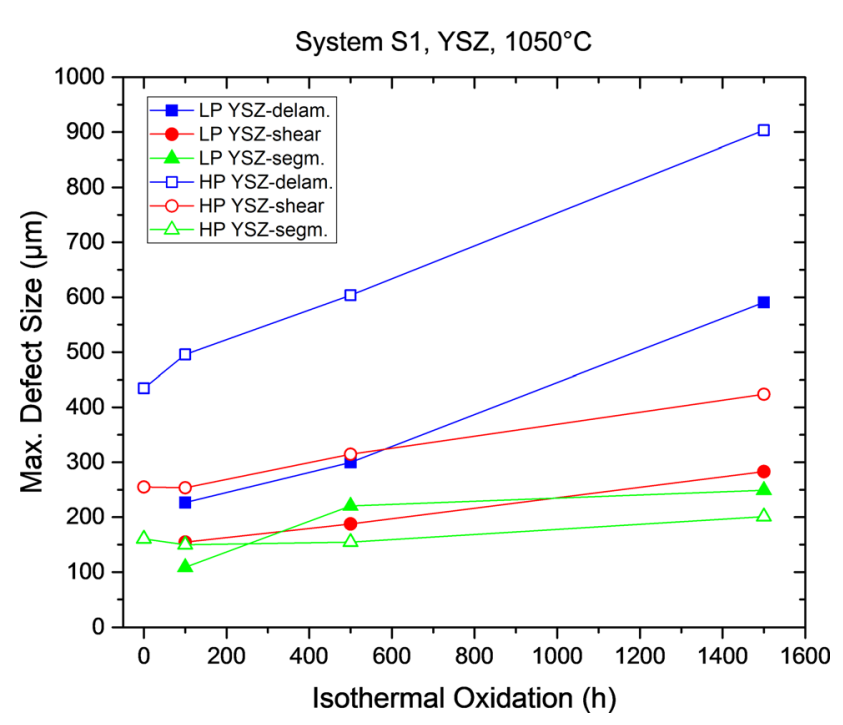

Fig. 6 Maximum defect size for the three categories delamination, shear and segmentation, determined from SEM images of YSZ (single-layer) coatings after isothermal oxidation at $1050{ }^{\circ} \mathrm{C}(\mathrm{HP}=$ higher porosity coating, open symbols; LP $=$ lower porosity coating, closed symbols).

delamination failure in compression was possible neither from the acoustic emission nor the stress-strain curve. Possibly, the interface adhesion to the bond coat is strong enough to suppress the delamination failure mode in compression. The critical strain values for YSZ shear failure drop slightly with longer exposure time from about $-1.8 \%$ (as-sprayed) to about $-1.4 \%\left(1500 \mathrm{~h}\right.$ at $\left.1050{ }^{\circ} \mathrm{C}\right)$ and $-1.3 \%\left(500 \mathrm{~h}\right.$ at $\left.1100{ }^{\circ} \mathrm{C}\right)$, respectively. No significant difference is observed between the two porosity levels. Tensile loading in the four-point bending configuration results in two distinct failure modes and consequently in two critical strain values for each exposure duration. At first, segmentation cracks start to develop at the top YSZ surface growing towards the bottom of the ceramic layer. When the segmentation cracks hit the ceramic/bond coat interface they get deflected and progress in the ceramic parallel to the interface. This leads to delamination of the ceramic top coat. The decrease in strain tolerance with prolonged isothermal oxidation is higher for the tensile failure modes, reducing from around $1.8 \%$ strain (assprayed) to around $0.3 \%$ strain $\left(1500 \mathrm{~h}\right.$ at $\left.1050{ }^{\circ} \mathrm{C}\right)$ for segmentation failure and $1.9 \%$ (as-sprayed) to around $1.0 \%$ $\left(1500 \mathrm{~h}\right.$ at $\left.1050{ }^{\circ} \mathrm{C}\right)$ for delamination failure, respectively. The decrease of the critical tensile strain values is also higher when oxidized at higher temperatures. The values drop to around $0.3 \%\left(500 \mathrm{~h}\right.$ at $\left.1100{ }^{\circ} \mathrm{C}\right)$ for segmentation failure and to around $1.1 \%\left(500 \mathrm{~h}\right.$ at $\left.1100{ }^{\circ} \mathrm{C}\right)$, respectively. Again, there is no significant difference observed between the two porosity levels. The decrease in critical strain with prolonged exposure can be attributed mainly to microstructural changes. In the initial stages of high-temperature exposure, rapid sintering of microporosity is observed leading to an increase in stiffness (Ref 15) and thus in a decrease of the critical strain values according to Eq 3.2 to 3.5. With further high-temperature exposure bond coat oxidation and thus growth of the alumina TGO layer will introduce stresses at the YSZ/bond coat interface region. The highest impact on mechanical degradation in the later stages of oxidation is, however, attributed to the crack formation upon cooling to room temperature (in combination with sintering of the ceramic during hightemperature exposure) due to the thermal expansion mismatch stresses between metallic substrate and ceramic top layer. It should be noted that, even though porosity may have a significant impact on TBC lifetime, the effect of porosity on critical strain observed in this work was relatively low in the case of the single-layer YSZ TBCs. The authors believe that this is due to the fact that the
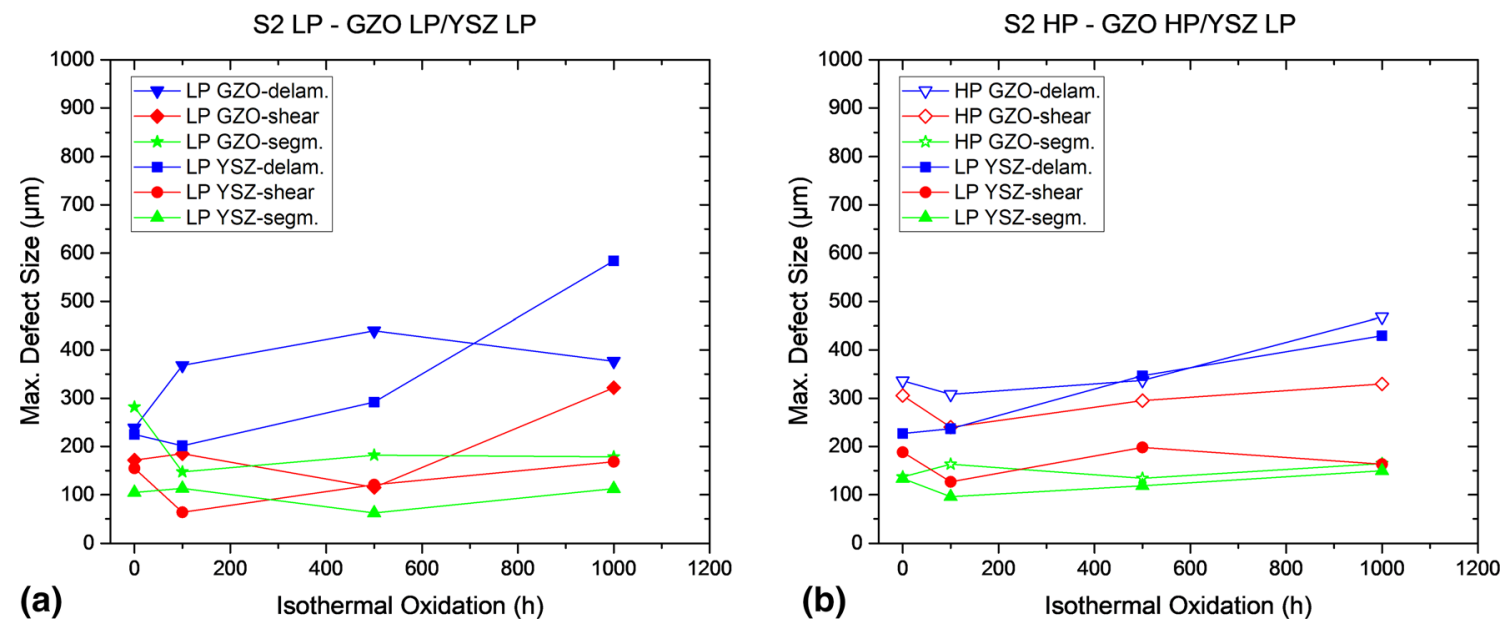

Fig. 7 Maximum defect size for the three categories delamination, shear and segmentation, determined from SEM images of GZO/YSZ (doublelayer) coatings after isothermal oxidation at $1050^{\circ} \mathrm{C}(\mathrm{HP}=$ higher porosity coating, open symbols; $\mathrm{LP}=$ lower porosity coating, closed symbols). 


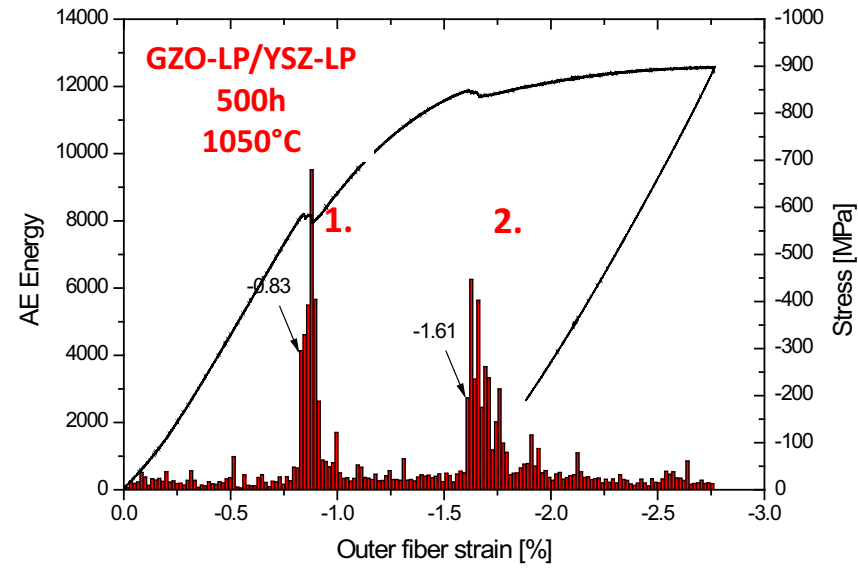

(a)

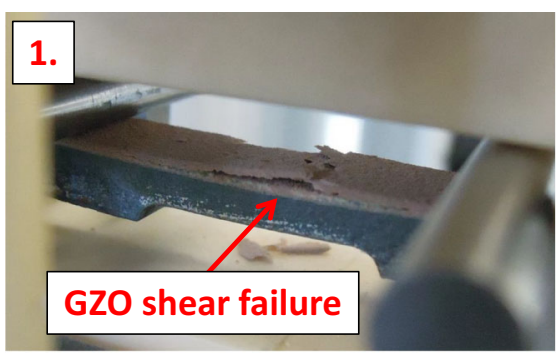

(b)

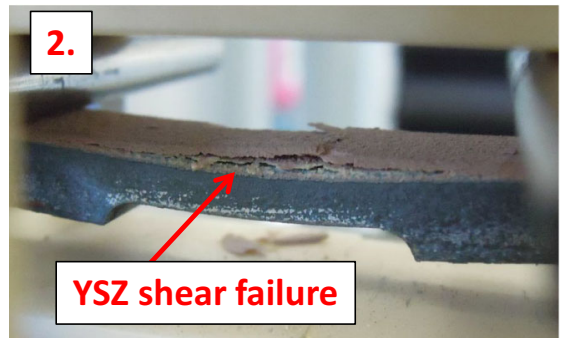

Fig. 8 Stress-strain-curve and acoustic emission signals obtained during four-point bending test of a GZO/YSZ double-layer TBC specimen (a), and optical observation of coating failure (b).

YSZ

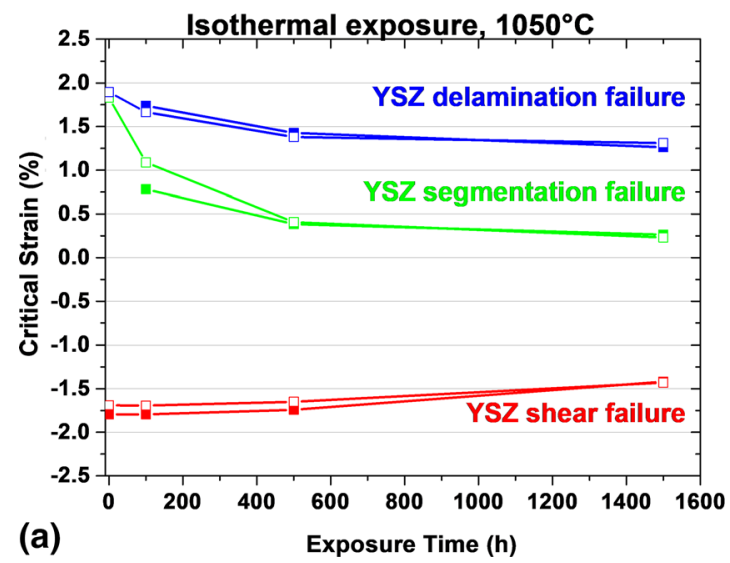

Fig. 9 Critical strain to failure of the ceramic YSZ top coat (singlelayer system S1) determined by four-point bending as a function of isothermal oxidation at $1050{ }^{\circ} \mathrm{C}$ and $1100{ }^{\circ} \mathrm{C}$, respectively (open

investigated oxidation durations are not long enough to lead to significant interaction of individual cracks, and that, with prolonged exposure the difference in physical defect size and critical strain will increase.

The behavior of the double-layer TBCs is depicted in Fig. 10. The critical strain to failure of the low-porosity and high-porosity variant of the coating is shown in (a) and (b), respectively. Note, the underlying YSZ coating is the low-porosity variant in both cases, only the top GZO layer was sprayed in two porosity levels. While in compressive loading two clearly separated peaks in the acoustic emission signal enabled us to distinguish the shear failure of GZO and YSZ, the acoustic signals recorded in tensile loading were overlapping for the different failure modes and impeded the data analysis. Nevertheless, data for GZO

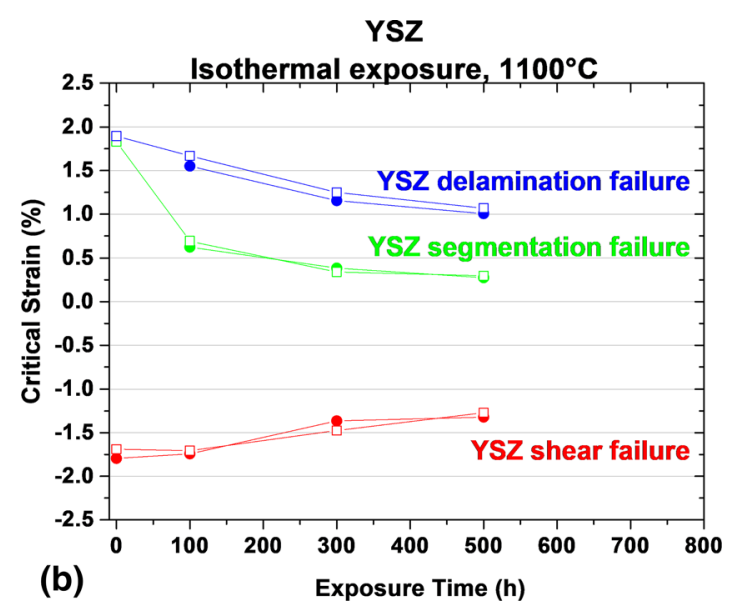

symbols $=$ higher porosity coating, HP; closed symbols = lower porosity coating, LP).

segmentation (from where the cracks continue to grow into the YSZ without significant change in the acoustic signal) as well as for GZO and YSZ delamination could be gained. As can be seen from the figure, the GZO top ceramic layer fails prior to the underlying YSZ layer and even at lower strain levels than the YSZ layer in the single-layer coating (cf. Fig. 9). This demonstrates the lower intrinsic fracture strength of GZO compared with YSZ as the failure strain was evaluated with taking the distance to the neutral fiber into account (c.f. Table 2). Under tensile load, the outer GZO layer is prone to segmentation-crack formation at similar values as the YSZ single-layer coating (e.g., $0.33 \%$ and $0.38 \%$ strain, respectively, for the LP variant after $500 \mathrm{~h}$ at $1050{ }^{\circ} \mathrm{C}$ ). However, delamination cracks start to form at $1.43 \%$ strain in the YSZ-LP coating but at only 


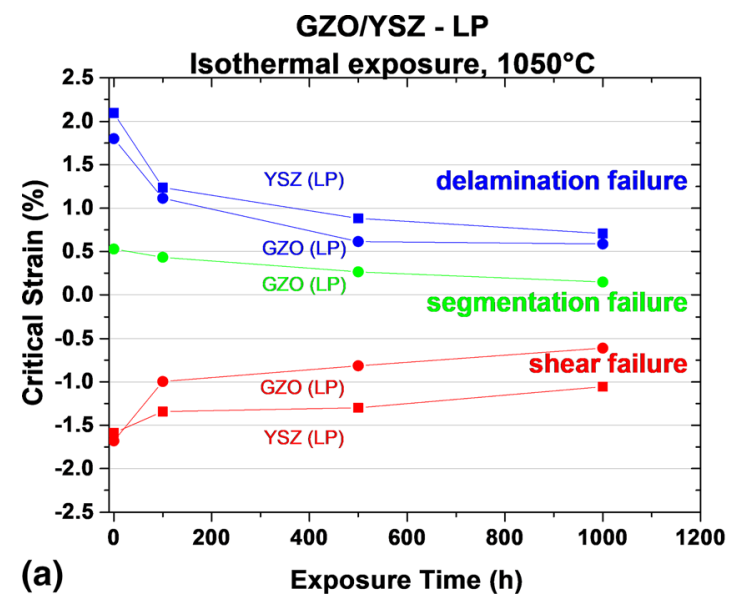

Fig. 10 Critical strain to failure of GZO/YSZ double-layer thermal barrier coatings determined by four-point bending as a function of isothermal oxidation at $1050{ }^{\circ} \mathrm{C}$, (a) low-porosity variant, (b) highporosity variant. Note, only the GZO top layer was sprayed with two

$0.61 \%$ strain in the GZO-LP coating. The strain tolerance of the GZO-LP layer under compressive loading is also significantly lower than that of the YSZ-LP coating (e.g., $-0.81 \%$ and $-1.74 \%$, respectively, after $500 \mathrm{~h}$ at $\left.1050{ }^{\circ} \mathrm{C}\right)$. The YSZ layer of the double-layer coating, however, remains only little affected by the failure of the top GZO layer, so that the failure of this bottom layer occurs at slightly lower strain levels (e.g., 1.03\% versus $1.43 \%$ strain for tensile shear failure and $-1.25 \%$ versus $-1.74 \%$ strain for compressive shear failure, after $500 \mathrm{~h}$ at $1050{ }^{\circ} \mathrm{C}$ ). The double-layer coating will hence preserve its protective function to some extent, after a loss of the GZO top layer. Comparing the two porosity levels of the GZO layer, it becomes evident that the high-porosity variant of the GZO coating exhibits lower mechanical strength, especially when considering the compressive shear failure. This is in accordance with the expected crack growth mechanism involving the interaction and coalescence of cracks, which should be accelerated when more pores and defects are present. And it is also in agreement with Griffith theory of brittle fracture with larger defects leading to lower fracture strain levels.

The overall lower strain tolerance of the GZO layer is attributed to the lower intrinsic fracture toughness of GZO but may also be affected by less experience in coating processing.

\section{Mechanical Stability Diagrams}

The equations given in Section 3 can be used to assess the theoretical critical strain values and to set up mechanical stability diagrams that describe the mechanical capability of a brittle material. This approach has been used in a very similar way to describe the failure of thermally grown

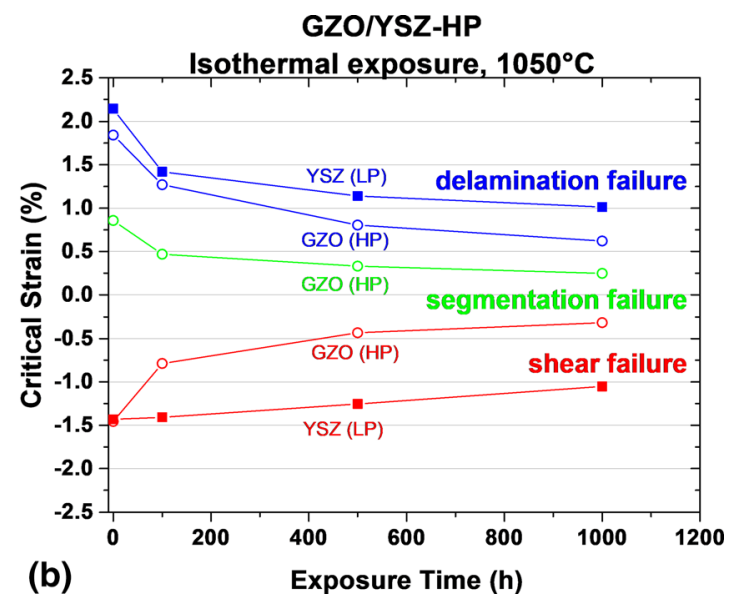

porosity levels [indicated as GZO (LP) and GZO (HP)], while the bottom YSZ layer was the low-porosity variant in both systems [YSZ (LP)].

oxide scales (Ref 22, 23). The dominant parameters governing the evolution of the observed macroscopic mechanical strength are the Young's modulus $E$ and the micro-defect structure (i.e., size $\mathrm{c}$ of the defect causing failure) in the ceramic coating. As a consequence of this, the presented approach should also implicitly cover further mechanisms that will generate microstructural damage in the ceramic coating, such as growth of the TGO layer. The fracture toughness $K_{\mathrm{c}}$ is a material constant in the context of Griffith's theory of brittle failure. It should be mentioned, however, that $K_{\mathrm{c}}$ (or rather a $K_{\mathrm{c}}$ value accessible by measurement as opposed to an atomistic single crystal value) is influenced by microstructural material characteristics such as grain structure (i.e., size and orientations), vacancy and dislocation concentrations and submicron defects and may thus vary over time. Nevertheless, the change in modulus and defect size observed in thermal barrier coatings will greatly dominate the evolution of the critical strain and hence modelling is focused on those two parameters, while treating the $K_{\mathrm{c}}$ as a constant. Since the shape factor $f$ in such a complex microcrack network is unknown, the combined factor $K_{\mathrm{c}} / f$ is used as fitting parameter. The defect growth kinetics presented in Fig. 6 and 7 reveal a mostly linear trend for the maximum defect size in the categories delamination and shear, whereas the segmentation cracks appear rather stagnant. Hence, a linear fit to the maximum crack length was used for each category to produce the data for $\mathrm{c}$ in the model. The in-plane stiffness for modelling was generated in a similar manner by exponential fitting of the experimental data measured by our project partners at TU Darmstadt on freestanding coatings (Ref 15). The equations used in the model for crack and stiffness evolution are given in Table 3, together with the resulting fitting parameter $K_{\mathrm{c}} / f$. By using separate 
equations for each individual coating layer, it is possible to capture the evolution of each system in a quite accurate way. It is worth noting that the values for $K_{\mathrm{c}}$ are in reasonable agreement with other experimental data by Dwivedi et al., where $K_{\mathrm{Ic}}$-values of about 4.0 to $4.5 \mathrm{MPa} / \mathrm{m}^{1 / 2}$ for sintered YSZ and around $1.5 \mathrm{MPa} / \mathrm{m}^{1 / 2}$ for GZO are reported (Ref 7). Assuming a shape factor $f$ for the tensile segmentation (mode I) failure of 0.64 (corresponding to a semicircular surface notch), the resulting values of this work for $K_{\text {Ic }}$ are $4.95 \mathrm{MPa} / \mathrm{m}^{1 / 2}$ and $3.19 \mathrm{MPa} / \mathrm{m}^{1 / 2}$ for
YSZ-LP and YSZ-HP, respectively and $2.72 \mathrm{MPa} / \mathrm{m}^{1 / 2}$ for the GZO-HP.

Figure 11 shows the modelled curves in comparison to the experimental critical strain values for the single-layer YSZ coating. The low-porosity variant of the single-layer YSZ coating is presented in subfigure (a), while the highporosity variant is given in (b). The areas where no coating failure is expected (safe operation) are colored in green, whereas areas in which damage is to be expected are colored in yellow (segmentation failure) and red (delamination or shear failure). In the early stages of oxidation

Table 3 Equations for defect size $c$ and stiffness $E$ of the ceramic layers used for modelling the critical strain to failure and derived fitting parameter $K_{\mathrm{c}} / f$ for the different failure modes.

\begin{tabular}{|c|c|c|c|c|c|}
\hline TBC system & Failure mode & Ceramic layer & $K_{\mathrm{c}} / f, \mathrm{MPa}^{*} \mathrm{~m}^{1 / 2}$ & $2 * c, \mu \mathrm{m}$ & $E, \mathrm{GPa}$ \\
\hline \multirow[t]{3}{*}{ YSZ-LP } & Tension segmentation & YSZ-LP & 3.15 & $132.10+0.087 * t$ & $49.64-16.29 * \exp (-(1 / 41.82) * t)$ \\
\hline & Tension delamination & YSZ-LP & 8.41 & $143.63+0.092 * t$ & $49.64-16.29 * \exp (-(1 / 41.82) * t)$ \\
\hline & Compression shear & YSZ-LP & 7.38 & $186.04+0.266^{*} t$ & $49.64-16.29 * \exp (-(1 / 41.82) * t)$ \\
\hline \multirow[t]{3}{*}{ YSZ-HP } & Tension segmentation & YSZ-HP & 2.03 & $149.90+0.031 * t$ & $33.50-9.12 * \exp (-(1 / 20) * t)$ \\
\hline & Tension delamination & YSZ-HP & 7.58 & $450.06+0.303 * t$ & $33.50-9.12 * \exp \left(-(1 / 20)^{*} t\right)$ \\
\hline & Compression shear & YSZ-HP & 6.11 & $250.54+0.117 * t$ & $33.50-9.12 * \exp (-(1 / 20) * t)$ \\
\hline \multirow[t]{6}{*}{ GZO/YSZ-LP } & Tension segmentation & GZO-LP & 3.80 & $146.56+0.130 * t$ & $68.8-42.9 * \exp (-(1 / 99.1) * t)$ \\
\hline & & YSZ-LP & $\ldots$ & $98.18+0.0^{*} t$ & $49.64-16.29 * \exp (-(1 / 41.82) * t)$ \\
\hline & Tension delamination & GZO-LP & 5.77 & $314.34+0.103 * t$ & $68.8-42.9 * \exp (-(1 / 99.1) * t)$ \\
\hline & & YSZ-LP & 5.40 & $177.77+0.370^{*} t$ & $49.64-16.29 * \exp (-(1 / 41.82) * t)$ \\
\hline & Compression shear & GZO-LP & 4.36 & $197.42+0.0 * t$ & $68.8-42.9 * \exp (-(1 / 99.1) * t)$ \\
\hline & & YSZ-LP & 4.40 & $106.30+0.052 * t$ & $49.64-16.29 * \exp (-(1 / 41.82) * t)$ \\
\hline \multirow[t]{6}{*}{ GZO/YSZ-HP } & Tension segmentation & GZO-HP & 1.73 & $144.28+0.014 * t$ & $60.7-38.1 * \exp (-(1 / 641) * t)$. \\
\hline & & YSZ-LP & $\ldots$ & $111.82+0.031 * t$ & $49.64-16.29 * \exp (-(1 / 41.82) * t)$ \\
\hline & Tension delamination & GZO-HP & 4.14 & $305.84+0.141 * t$ & $60.7-38.1 * \exp (-(1 / 641) * t)$. \\
\hline & & YSZ-LP & 4.74 & $225.79+0.211 * t$ & $49.64-16.29 * \exp (-(1 / 41.82) * t)$ \\
\hline & Compression shear & GZO-HP & 2.28 & $271.21+0.053 * t$ & $60.7-38.1 * \exp (-(1 / 641) * t)$. \\
\hline & & YSZ-LP & 4.90 & $166.22+0.007 * t$ & $49.64-16.29 * \exp (-(1 / 41.82) * t)$ \\
\hline
\end{tabular}
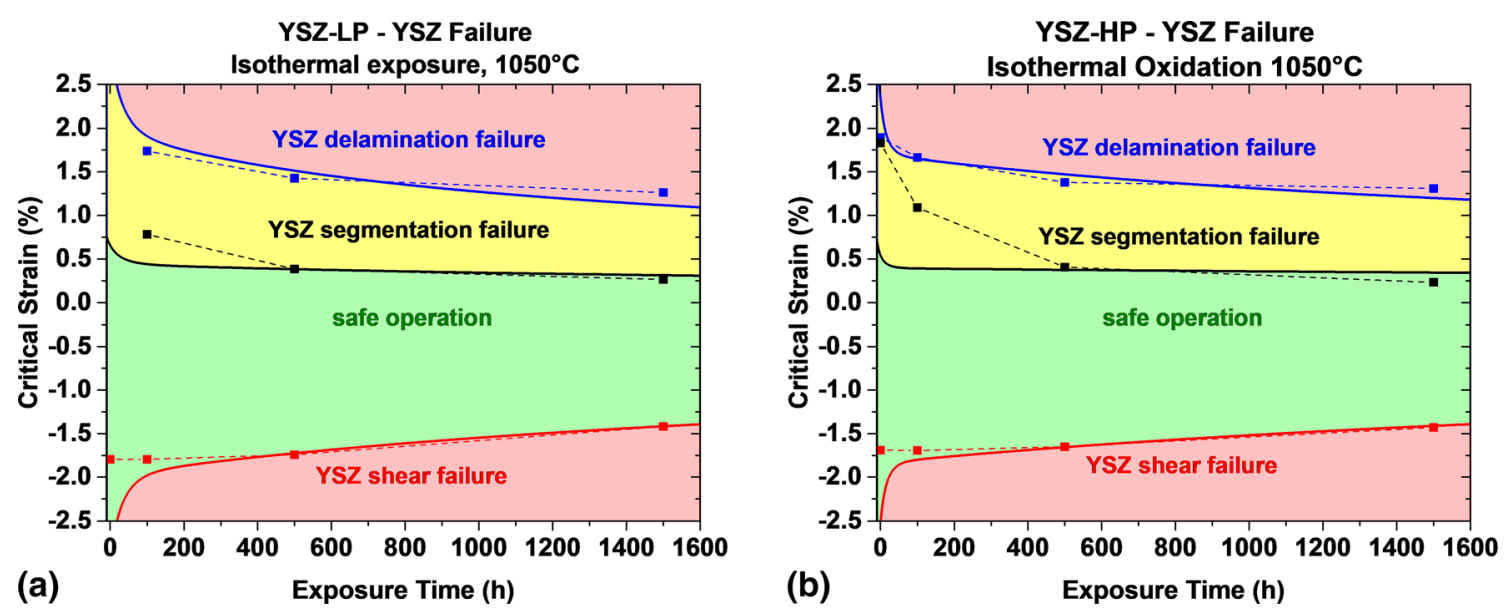

Fig. 11 Mechanical stability diagrams for the investigated YSZ thermal barrier coatings. The failure curves delineate areas of safe operation from areas where failure becomes imminent. Data points are results from four-point bending test. 

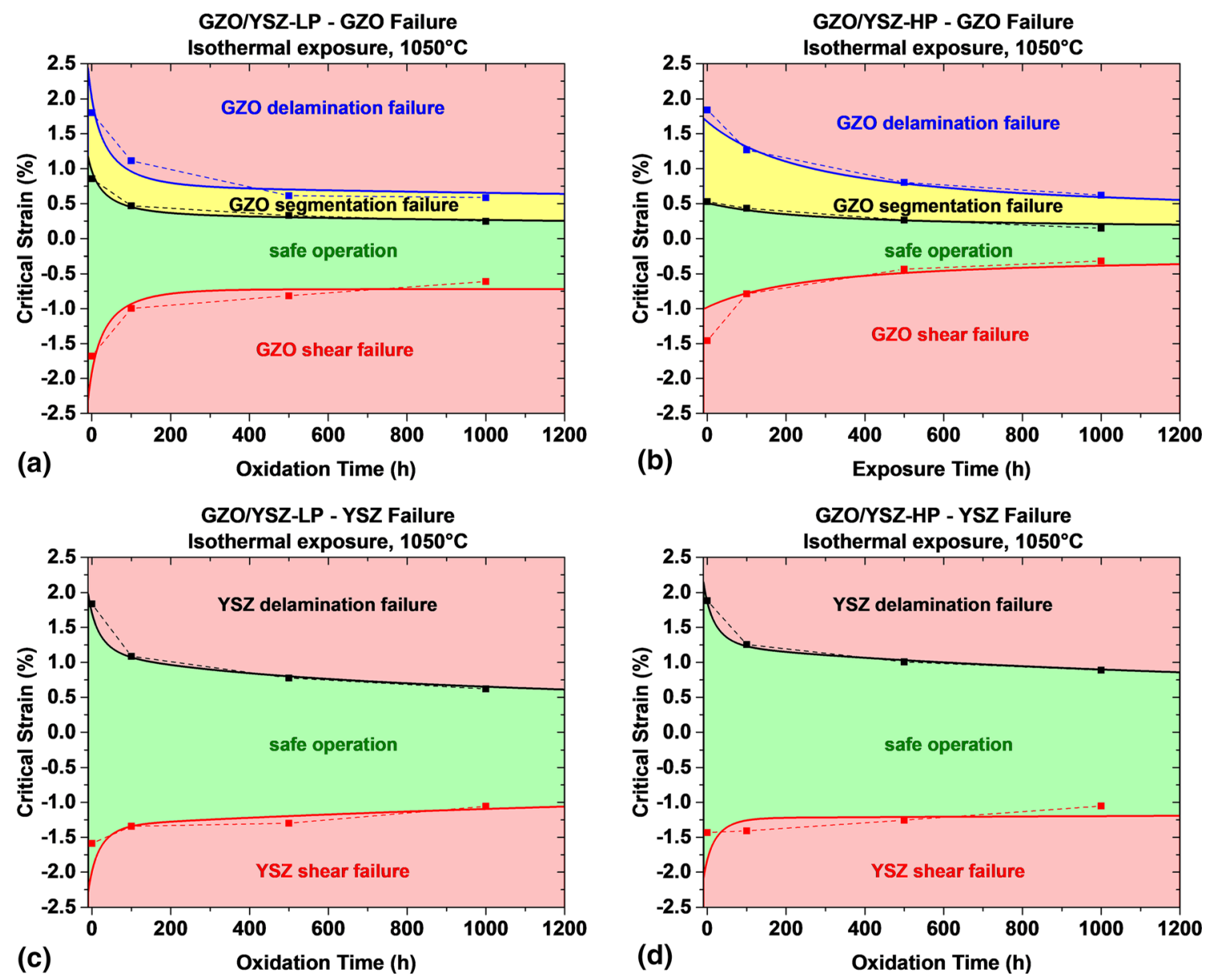

Fig. 12 Mechanical stability diagrams for the investigated GZO/YSZ double-layer coatings. The failure curves delineate areas of safe operation from areas where failure becomes imminent. Data points are results from four-point bending test.

$(<500 \mathrm{~h})$, the agreement of the model with the experimental data is limited. This is probably due to differences in the evolution of the coating stiffness between the fourpoint bending specimens (constrained sintering) and the freestanding TBC samples (free sintering) used to generate the stiffness data. The results for the double-layer system are given in Fig. 12 demonstrating the lower strain tolerance of the investigated GZO layer by a much smaller green area of "safe operation" (Fig. 12a and b). The successive failure of the underlying YSZ layer is represented by the subfigures Fig. 12c and d. The YSZ layer remains intact upon failure of the GZO top layer and can withstand higher strain levels than the GZO. In a similar way as the single-layer system, the agreement between modelled curves and experimental data in the very early stages is limited. Nevertheless, the model demonstrates how individual properties influence the mechanical capability of multilayered coating systems and how the mechanical behavior of complex ceramic systems can be modelled based on fracture mechanics. The mechanical capability of the GZO/YSZ double-layer is lower than that of the YSZ single-layer. This may partly be due to the lower intrinsic fracture toughness of gadolinium zirconate, but also due to the fact that there is significantly less experience in spray processing GZO coatings compared to decades of coating experience with YSZ coatings. Apparently, spray processing can have significant impact on properties and lifetime of GZO coatings (Ref 24, 25).

\section{Conclusions}

Mechanical four-point bend testing with acoustic emission measurement was used to investigate the strain tolerance of novel double-layer GZO/YSZ thermal barrier coatings in comparison with state-of-the-art single-layer YSZ coatings. The investigated GZO/YSZ double-layer coating exhibits lower mechanical strength than the benchmark single-layer YSZ coating. The lower observed failure strain is partly due to the fact that the intrinsic fracture toughness of GZO is lower than that of YSZ, but may also have a contribution from less experience with processing of GZO coatings, 
since optimization of spray parameters was shown to play a critical role in the performance of GZO coatings. The two investigated porosity levels of the ceramic coatings exhibited different levels of mechanical strength, with the lower porosity variant resulting in higher critical strain values, which is in accordance with Griffith's theory of brittle fracture.

In combination with physical property data, the critical strain measurements enable the determination of novel mechanical stability diagrams for thermal barrier coatings. The mechanical stability diagrams can serve to distinguish fields of save operation from operational conditions where mechanical failure may occur for each individual coating layer.

With these diagrams, it is thus possible to assess and define operational limits (in terms of strain) and to estimate the mechanical lifetime of thermal barrier coatings. However, precise knowledge of the defect growth kinetics is required for adequate extrapolation and the database of the investigated systems is still too limited for such task. Hence, if the presented model were to be used for industrial lifetime assessment, a more detailed investigation of the defect growth is advised and longer exposure durations should be investigated.

Acknowledgments This work was funded by the German Research Foundation (Deutsche Forschungsgemeinschaft, DFG, Grant No. SCHU 729/25) and the German Research Association for Combustion Engines (Forschungsvereinigung Verbrennungskraftmaschinen e.V., FVV, Grant No. 1108) which is gratefully acknowledged. We also thank the German working group "Thermal Barrier Coatings" of the FVV under chairmanship of Dr. Werner Stamm, Siemens AG, for their guidance and scientific discussion. Additional financial support for coating processing and substrate material was provided by Siemens AG, ALSTOM (Switzerland) Ltd., MAN Turbo \& Diesel SE, Rolls-Royce Deutschland Ltd. \& Co. KG and MTU Aero Engines $\mathrm{GmbH}$, which is also gratefully acknowledged. Special thanks go to our project partners Dr. Martin Frommherz, IfW, TU Darmstadt and Dr. Emine Bakan, IEK-1, FZ Jülich for sharing stiffness data and porosity data, respectively.

Funding Open Access funding enabled and organized by Projekt DEAL.

Open Access This article is licensed under a Creative Commons Attribution 4.0 International License, which permits use, sharing, adaptation, distribution and reproduction in any medium or format, as long as you give appropriate credit to the original author(s) and the source, provide a link to the Creative Commons licence, and indicate if changes were made. The images or other third party material in this article are included in the article's Creative Commons licence, unless indicated otherwise in a credit line to the material. If material is not included in the article's Creative Commons licence and your intended use is not permitted by statutory regulation or exceeds the permitted use, you will need to obtain permission directly from the copyright holder. To view a copy of this licence, visit http://creativecommons. org/licenses/by/4.0/.

\section{References}

1. T.E. Strangman, Thermal Barrier Coatings for Turbine Airfoils, Thin Solid Films, 1985, 127(1-2), p 93-106.

2. S.M. Meier, D.K. Gupta and K.D. Sheffler, Ceramic Thermal Barrier Coatings For Commercial Gas Turbine Engines, JOM, 1991, 43(3), p 50-53.

3. D.R. Clarke, M. Oechsner and N.P. Padture, Thermal-Barrier Coatings for More Efficient Gas-Turbine Engines, MRS Bull., 2012, 37(10), p 891-898.

4. R.A. Miller, J.L. Smialek, and R.G. Garlick, Phase Stability in Plasma-Sprayed, Partially Stabilized Zirconia-Yttria, Science and Technology of Zirconia, The American Ceramic Society, 1981, p 241-253.

5. G. Witz, V. Shklover, W. Steurer, S. Bachegowda and H.-P. Bossmann, Phase Evolution in Yttria-Stabilized Zirconia Thermal Barrier Coatings Studied By Rietveld Refinement of X-Ray Powder Diffraction Patterns, J. Am. Ceram. Soc., 2007, 90(9), p 2935-2940.

6. R. Vassen, X. Cao, F. Tietz, D. Basu and D. Stöver, Zirconates as New Materials for Thermal Barrier Coatings, J. Am. Ceram. Soc., 2000, 83(8), p 2023-2028.

7. G. Dwivedi, V. Viswanathan, S. Sampath, A. Shyam and E. LaraCurzio, Fracture Toughness of Plasma-Sprayed Thermal Barrier Ceramics: Influence of Processing, Microstructure, and Thermal Aging, J. Am. Ceram. Soc., 2014, 97, p 2736-2744.

8. R. Vassen, A. Stuke and D. Stöver, Recent Developments in the Field of Thermal Barrier Coatings, J. Therm. Spray Technol., 2009, 18(2), p 181-186.

9. D. Stöver, G. Pracht, H. Lehmann, M. Dietrich, J.-E. Döring and R. Vaßen, New Material Concepts for the Next Generation of Plasma-Sprayed Thermal Barrier Coatings, J. Therm. Spray Technol., 2004, 13(1), p 76-83.

10. D.P. Renusch, H. Echsler and M. Schütze, The Role that Interacting Failure Mechanisms Have on the Lifetime of APS-TBC Under Oxidizing Conditions, Mater. Sci. Forum, 2004, 461-464, p 729-736.

11. D.P. Renusch, H. Echsler and M. Schütze, Progress in Life Time Modeling of APS-TBC Part I: Residual, Thermal and Growth Stresses Including the Role of Thermal Fatigue, Mater. High Temp., 2004, 21(2), p 65-76.

12. H. Echsler, D.P. Renusch and M. Schütze, Bond Coat Oxidation and Its Significance for Life Expectancy of Thermal Barrier Coating Systems, Mater. Sci. Technol., 2004, 20, p 307-318.

13. A.A. Griffith, The Phenomena of Rupture and Flow in Solids, Philos. Trans. R. Soc. Lond. A, 1921, 221(1), p 163-198.

14. D.P. Renusch, H. Echsler and M. Schütze, Progress in Life Time Modeling of APS-TBC Part II: Critical Strains, Macro-Cracking, and Thermal Fatigue, Mater. High Temp., 2004, 21(2), p 1-13.

15. M. Frommherz, A. Scholz, M. Oechsner, E. Bakan and R. Vaßen, Gadolinium Zirconate/Ysz Thermal Barrier Coatings: MixedMode Interfacial Fracture Toughness and Sintering Behavior, Surf. Coat. Technol., 2016, 286, p 119-128.

16. J. Schindelin, I. Arganda-Carreras, E. Frise, V. Kaynig, M. Longair, T. Pietzsch, S. Preibisch, C. Rueden, S. Saalfeld, B. Schmid, J.Y. Tinevez, D.J. White, V. Hartenstein, K. Eliceiri, P. Tomancak and A. Cardona, Fiji: An Open-Source Platform for Biological-Image Analysis, Nat. Methods, 2012, 9, p 676.

17. P. Hancock and J.R. Nicholls, Application of Fracture Mechanics to Failure of Surface Oxide Scales, Mater. Sci. Technol., 1988, 4(5), p 398-406.

18. G.R. Irwin, Analysis of Stresses and Strains Near the End of a Crack Traversing a Plate, J. Appl. Mech., 1957, 1957(24), p 361-364. 
19. M. Schütze, D.R. Holmes and R.B. Waterhouse, Protective Oxide Scales and Their Breakdown, Wiley, Chichester, 1997.

20. G.E. Dieter, Mechanical Metallurgy, 2nd ed. McGraw-Hill, New York, 1976.

21. R.A. Sack, Extension of Griffith's Theory of Rupture to Three Dimensions, Proc. Phys. Soc., 1946, 58(6), p 729.

22. M. Rudolphi and M. Schütze, Investigations for the Validation of the Defect Based Scale Failure Diagrams-Part I: Nickel Oxide, Oxid. Met., 2013, 79(3-4), p 167-177.

23. M. Rudolphi and M. Schütze, Investigations for the Validation of the Defect Based Scale Failure Diagrams-Part II: Extension of the Concept and Application to Nickel Oxide, Titanium Oxide and Iron Oxide, Oxid. Met., 2015, 84(1-2), p 45-60.
24. E. Bakan, D.E. Mack, G. Mauer and R. Vaßen, Gadolinium Zirconate/Ysz Thermal Barrier Coatings: Plasma Spraying, Microstructure, and Thermal Cycling Behavior, J. Am. Ceram. Soc., 2014, 97(12), p 4045-4051.

25. E. Bakan, D.E. Mack, G. Mauer, R. Mücke and R. Vaßen, Porosity-Property Relationships of Plasma-Sprayed $\mathrm{Gd}_{2} \mathrm{Zr}_{2} \mathrm{O}_{7} /$ Ysz Thermal Barrier Coatings, J. Am. Ceram. Soc., 2015, 98(8), p 2647-2654.

Publisher's Note Springer Nature remains neutral with regard to jurisdictional claims in published maps and institutional affiliations. 